\title{
Femoral stem-bone interface analysis of logical uncemented stem
}

Leandro de Freitas Spinelli*, Carlos Alberto de Souza Macedo, Carlos Roberto Galia, Ricardo Rosito, Fernando Schnaid, Leandro Luis Corso, Ignácio Iturrioz

\begin{abstract}
This paper evaluates the mechanical behavior of an uncemented hip stem using finite element analysis. The analysis is focused on the stem-bone interaction which is assessed by simulation of distinct conditions encountered daily on orthopedic practice of hip implants. Logical uncemented femoral stem was used in this work. Three distinct conditions have been modeled: a) exposed neck with fully embedded fins, b) partially exposed anti-rotational fins and c) fully exposed fins, representing real femoral hip conditions. Anthropometric variations and different angulations for the stem neck were investigated for typical body weight of populations submitted to implants. The ratio of mobilized stress to yield stress is shown to be lower than $55 \%$ indicating a safety factor against stem failure. Although small displacements are observed in all conditions, the displacement increases with the increase of both the length of exposed fins and the magnitude of applied forces. Even for the extreme condition of fully exposed fins, the prostheses will support the working loads, and the risk of bone fracture still has a safety factor. Stresses and displacements change considerably with neck angulations suggesting that anthropometric variations should be considered in the future to optimize prostheses performance. Numerical analysis of the used uncemented femoral stem demonstrated that small stresses and strains are generated under working load conditions indicating that a proper factor of safety is obtained for the static conditions tested in the present study.
\end{abstract}

Keywords Numerical analysis, Hip surgery, Uncemented stem, Prosthesis.

\section{Análise numérica do comportamento biomecânico da haste femoral não-cimentada Logical}

Resumo A presente pesquisa avalia o comportamento mecânico da haste femoral não-cimentada Logical através de elementos finitos. Foram analisadas diferentes condições de contorno encontradas na prática ortopédica: a) apenas o colo exposto; b) com as aletas anti-rotatórias parcialmente expostas; e c) com as aletas totalmente expostas. Variações antropométricas foram consideradas pelas diferentes angulações de colo propostas e através de diferentes cargas aplicadas. A haste apresentou um bom coeficiente de segurança. Embora pequenos deslocamentos sejam observados em todas as condições, existe um maior deslocamento com o aumento da exposição das aletas da prótese. Mesmo para a condição extrema com as aletas totalmente expostas, a prótese suporta as cargas de trabalho e ainda há um bom fator de segurança. Tensões e deslocamentos se modificam consideravelmente com as diferentes angulações propostas para o colo, sugerindo que as variações antropométricas devam ser consideradas no futuro para otimizar o desempenho da prótese.

Palavras-chave Análise numérica, Cirurgia do quadril, Haste femoral não-cimentada, Prótese de
quadril. 


\section{Introduction}

Due to the high success rates of orthopedic surgery procedures, total hip joint replacement has increased significantly over last decades mainly due to population ageing. Surgery is recommended in several cases of hip damage when the damaged cartilage and bone are removed from the hip joint and replaced with new man-made parts. This imposes the challenge of carrying out biomechanical studies that are aimed at evaluating the performance of metal alloys, high-grade plastics and polymeric materials to produce highly functional and long-lasting prosthesis. Part of these studies can be done by finite element analysis used to simulate hip joint replacement performance.

A hip implant is designed to substitute an anatomical proximal femoral and acetabular part and therefore must consider parameters such as: stem length, cross-section, neck length, and neck angle, biocompatibility of materials (Bennet and Goswami, 2008). This is to ensure that the femoral stem and cups can functionally resist as a hip articulation to be used primarily in arthroplasty, revisions and reconstruction of proximal femur (Macedo, 2007). Among several other advances in the design, construction and implantation of artificial hip joints, attentions is given to the first Brazilian cementless stem validated by both International and Brazilian national standards (ASTM and ABNT/NBR) designed by Macedo (2007) and Macedo et al. (2008). This stem has been widely used in the Faculty Hospital of the Federal University of Rio Grande do Sul, southern Brazil, with more than 1000 units implanted, and 7100 units in Brazil. Also, the stem is a low-cost option for use in Brazilian Public Medical Assistance (SUS).

Since the clinical success of an implant is largely determined by the manner in which the mechanical forces are transferred from the implant to the surrounding bone without generating plastic stresses and permanent strains (that would risk its long-term performance), there is a need to estimate the biomechanical transfer forces involved in the design of the implant. The finite element method is known to be a valuable tool to simulate many biomechanics applications, including orthopedics, as already demonstrated by reported design experiences on joint replacement prostheses carried out either by manufacturers or by university laboratories (Brekelmans et al., 1972; Macedo et al., 2008; Prendergast, 1997). After early efforts from Brekelmans et al. (1972) reporting the first finite element analysis (FEA) of the femur, 3D FEA has been successfully used to evaluate several different prostheses (Bennet and Goswami, 2008; Fagan and Lee, 1986; Huiskes and Van Rietbergen, 1995; Keaveny and Bartel, 1993; McNamara et al., 1997; Prendergast et al., 1989; Tanner et al., 1995;
Verdonschot, 1995; Verdonschot et al., 1993; Yettram, 1989), as well as to optimise designs (Fernandes et al., 2004; Yu et al., 2002). Sakai et al. (2010) investigated some aspects related to initial stability after stem fixation by finite element models on cementless stem. Relative micromotion of the cementless stem showed a value as low as that of a conventional stem. The authors concluded that based on the relative micromotion and von Mises stress level, the cementless stem showed initial stability.

Although numerical analysis is not fully incorporated to medical studies, there are a number of valuable contributions. Huiskes and Vroemen (1986) introduced the concept of pre-clinical evaluation by previewing maximum normal stress and shearing of interfaces for different prostheses models, whereas Brown and Callaghan (2008) revised the impingement and its dislocations by finite element method, focusing on implant variables, its implantations and patient's activities. Ahmet et al. (2007) investigated contact mechanics and stress distribution in resurfacing with metallic cups. Kluess et al. (2009) presented an algorithm based on analyzed bone by computed tomography of an implant model to simulate bone stress and interface implant mechanisms. A human frozen hemi-pelvis was analyzed with an acetabulum implant with loading cycles measurements compared to finite element models, showing strong correlation between measured and estimated deformations.

As for the bone, simulation is differently from other biological tissues. Modeling and simulation are well established given to its relatively high stiffness and straight forward application in static solid modeling. Although some research groups have defined the geometry of the bone in a generic manner using measurements from in vitro specimens, it is becoming more common to extract bone geometry from medical scans such as computed tomography (CT) and magnetic resonance imaging (MRI) images (Jones, 2009).

Having described these early reported experiences, it is important to clarify that FEA may not produce a precise assessment of mobilized operational forces, but it does provide means of performing parametric studies conceived to optimize the geometric characteristics of an implant for a given set of material parameters (Huiskes, 1991; Lee, 1987; Prendergast, 1997). For this reason this approach has been adopted in the present work to evaluate the biomechanical behavior of an uncemented designed femoral stem.

\section{Materials and Methods}

The Logical CM (TM) uncemented stem used in this paper was designed by Macedo (2007), and was chosen for the present study due to its adequate 
characteristics and tested performance. The designed stem presents some features of the original CLS Spotorno hip stem (Zimmer, Switzerland) and is very similar to AI-Hip cementless stem (Aimedic, Italy) used by Sakai et al. (2010), with a characteristic quadrangular and cuneiform stem with fins in the two symmetrical faces that have been designed to provide a better stem-bone interaction and tortional stability. One advantage of the Logical CM is related to the thinner and sharper blades designed to produce a better cementless fixation to the bone: blades are covered by plasma-spray porous coating with a unique microporosity to promote adequate surface for bone ingrowth (Macedo, 2007; Macedo et al., 2008) (Figure 1). The stem is made in Titanium Ti6Al4V ELI Alloy according to ASTM F136 (American..., 2008a) and NBR-ISO 5832-3 (Associação..., 1997) recommendations. The stem neck is positioned in neutral and cervical-diafisary angle of $135^{\circ}$ having a Morse cone of 12-14 mm to allow 22, 26 and $28 \mathrm{~mm}$ modular femoral head diameters to be connected to short, medium and large neck lengths.

The material properties for the implant were assumed to be isotropic and linear elastic, obeying Hooke's Law. The implant was assumed to transmit all absorbed energy to the surrounding environment and the effects of body heat were neglected to cause any creep effects. For this analysis, sizes of head diameter have not been modeled which implies on considering that forces are applied at its natural position at the femoral neck. This simple model is easily implemented and has been proved efficient in the simulation of biomechanical problems. More complex models incorporating anisotropy will be considered in future work. From the mathematical point of view, the Von Mises criteria was used to compute normal and shear stresses, which is a classical approach in the engineering field specially to estimate the yield stress. Mesh-refinements schemes have been tested in points of greater stress increase and numerical results obtained from the analysis show displacement and stress convergence everywhere in the joint.

The way the implants are treated and modeled in this paper deserves careful consideration. The anatomical condition of a particular patient can be obtained by computer tomography (CT) images and matrices, from which bone mineral density is captured. Although these three-dimensional imaging data can be converted into finite-element meshes for continuum mechanics computation of specific biomedical problems, a more general approach was adopted here by simulating general conditions that are commonly encountered in daily orthopedic practice. When the natural condition of a hip is changed by prostheses, the cancellous bone is milled and removed and the femoral stem is introduced by press fit. Femoral osteotomy is currently used for arthroplasties, as the prosthesis is generally fully inserted with only the neck of the femur exposed (Figura 2a). This Figure 2a presents a hip radiograph and the relationship between proximal bone and femoral stem just after the surgical procedure, showing the direct contact area between the implant surface and the cortical bone. There are cases, however, in which this standard condition is not achieved, when the femur anatomy is unusual due to small or large bone defects. In order to keep the biomechanics of the hip, it is necessary in these cases to partially expose the stem to avoid limb shortening (Figure 2b). In extreme cases, when there are large bone defects, revision prosthesis, endoprosthesis or even a standard prosthesis can be used (Figura 2c). This complex boundary conditions can be simplified allowing the system to be modeled by taking only two materials into consideration (cortical bone and the implant), the bone being assumed as isotropic and linear and the implant inserted in a homogeneous cylindrical bone vessel (Figures 3d-f).

The model for stress and displacement analyses was meshed with three dimensional, 10 node tetrahedral solid elements. Both of bone and implant meshes were assumed to be in contact with each other by means of using adjoining nodes for each of the meshes. Material properties of the hip implant and the bone are summarized in Table 1.

The prototype implant has been designed in Autocad (Autodesk, Inc.) (Figure 1a) and SolidWorks (Dassault Systèmes, SolidWorks Corp.) (Figure 3a) to allow for an accurate discretization in a $3 \mathrm{D}$ finite element mesh representation, as illustrated in Figure $3 b$. The numerical analysis has been performed in Finite Element Method using the commercial Package ANSYS 10 (ANSYS, Inc.). This model was build

Table 1. Mechanical properties of bone and stem.

\begin{tabular}{cccc}
\hline Material & Elastic modulus (MPa) & Critic limit (MPa) $^{\mathbf{1}}$ & Poisson's ratio $^{\text {(Ti6Al4V) }}{ }^{2}$ \\
\hline Stem $($ Ti6 & 134300 & 930 & 0.36 \\
Bone $^{3}$ & 10000 & 224 & 0.20 \\
\hline
\end{tabular}

${ }^{1}$ Critic limit is obtained as plastic limit for the stem and ultimate compression stress for bone. ${ }^{2}$ Measured from laboratory unconfined compression tests. ${ }^{3}$ Mean values obtained from reported data. 
with 36585 tetrahedral elements with 10 nodes per element and three degree of freedom per node. 28439 elements were used to model the stem and 8146 the cylindrical vessel that represent the bone where the implant is fitted. Perfect contact between implant and bone is assumed. Since typical patient's weight lies within 50 to $120 \mathrm{~kg}$, forces applied to stem ranged from 500 to $4800 \mathrm{~N}$ to simulate natural conditions found in vivo (Figure 3c), considering that total hip force may reach four times body weight in special circumstances (Harkess and Crockarell, 2007; Lewis et al., 2010). Hip, as any other joint in human body, presents a complex force system whose intensity, point of application and direction depends
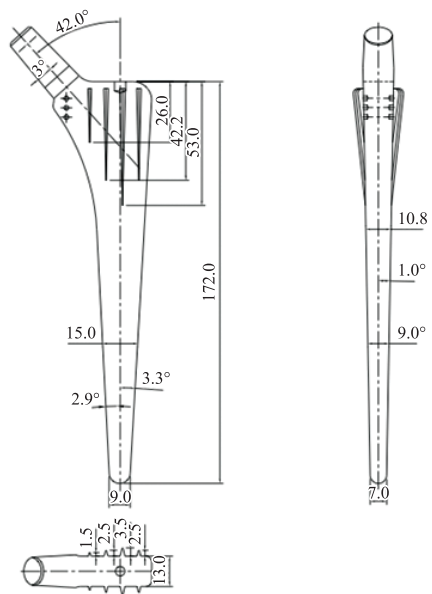

(a)
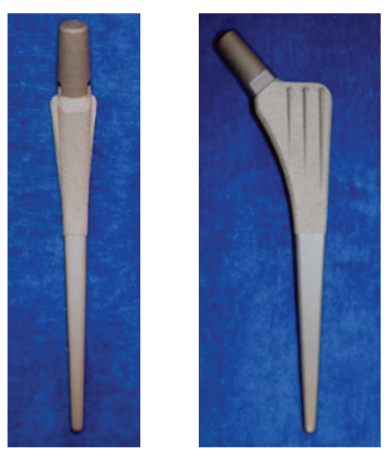

(b)

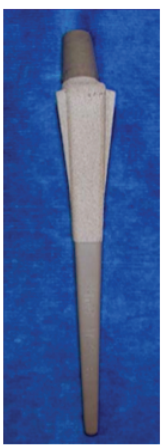

Figure 1. Uncemented femoral stem used for the experiments: a) design sketch for the Logical CM stem (sizes are in millimeters and angles in degrees); b) actual stem.

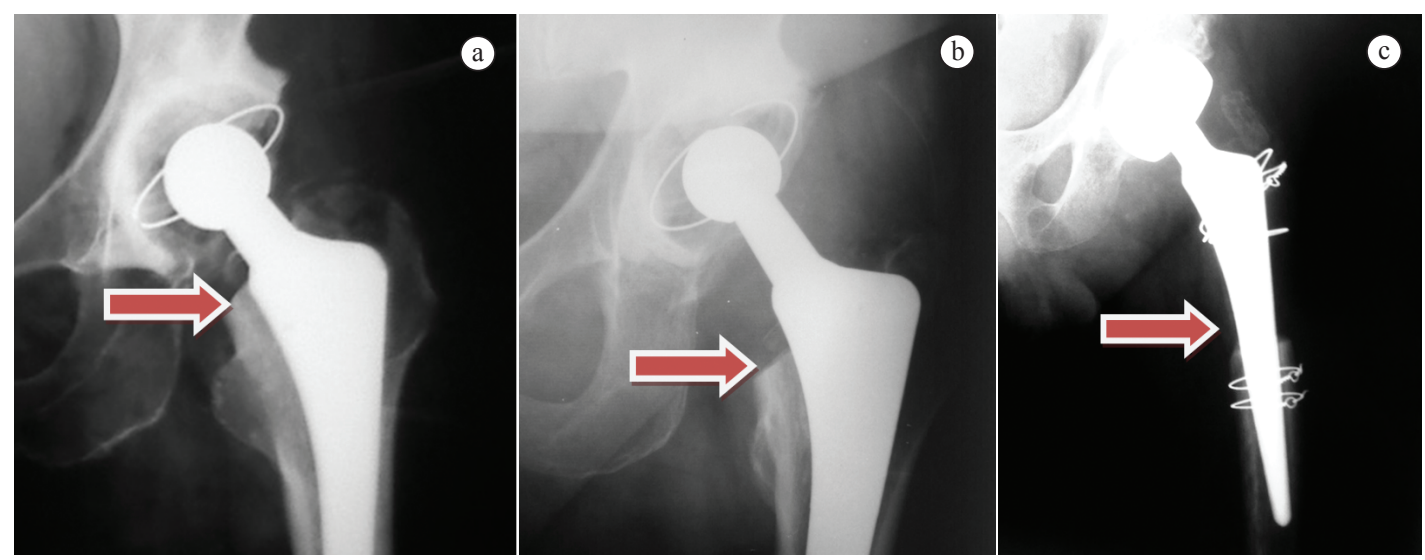

Figure 2. Observed X-ray hip conditions usually found in orthopedic practice: a) only neck exposed; b) partially exposed fins; and c) fully exposed fins. 

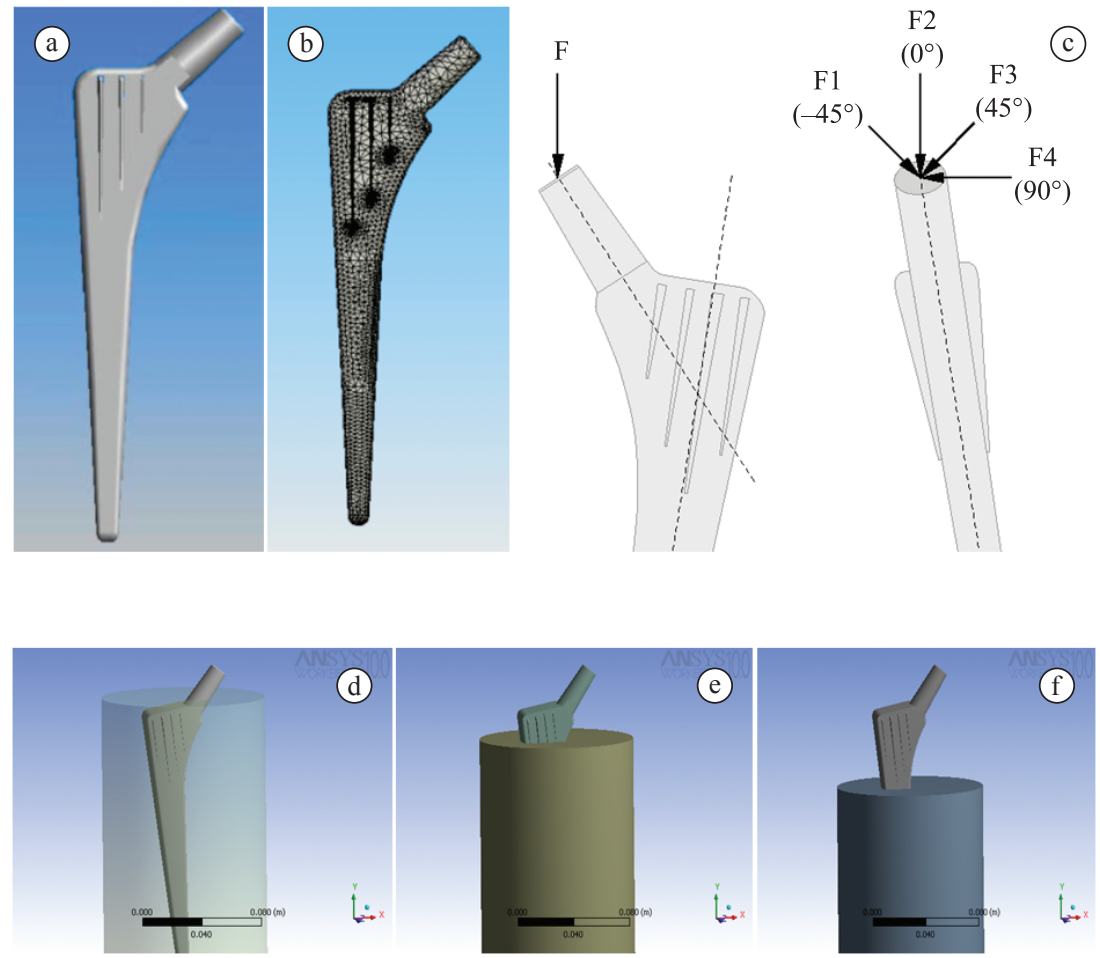

Figure 3. a) 3d SolidWorks generated stem; b) finite element mesh; c) force application/orientation observed in frontal and lateral views; $d$, $\mathrm{e}$ and f) numerical model of stem and cylindrical vessel that represent the bone for the three evaluated conditions.

on many variables. In addition, the resulting force varies throughout the whole gait cycle. It can even be possible, theoretically, that the maximum stress occurs out of the maximum load zone. Some special conditions varying force directions were applied for that consideration simulating flexion-extension (flexion of +90 degrees up to extension of -45 degrees).

Three distinct conditions have been modeled, as discussed before, for the real conditions simulations: a) exposed neck with fully embedded fins, b) partially exposed anti-rotational fins, and c) fully exposed fins (Figure 3d-f), representing real femoral hip conditions seen in Figure 2. When an arthroplasty is performed for the first time in arthrosis, near to normal anatomical configurations are seen, once fractures or other diseases did not perturbed the bone. However, the presence of a deficient or mechanically compromised proximal femur represents a particular challenge to surgeries in the cases of dysplasia, fractures, tumors or revision total hip arthroplasty, once a lack in bone stock is observed. Although a complete fixation cannot be achieved in cases where the proximal femur is absent, there is still a chance of success in these difficult conditions (Figures 2b, c). In extreme cases, the implant would be fixed distally, acting as a fixed and embedded beam. These various conditions of femoral exposure have been evaluated in the current study by assessing whether the lack of proximal bone alters the transfer forces to the stem.

Despite being an important topic, osteointegration was not the focus of this work, but the immediate post-operative condition, given the fact that many surgeons allow the immediate bearing support of patients in the days following surgery. Considering the subsequent osteointegration, theoretically there would be an improvement in the boundary conditions.

In addition, there are also some cases where the prostheses design may have to adapt to the patient anatomy. Since most patients have a cervix-diaphisary angle ranging from $110^{\circ}$ to $160^{\circ}$, single fixed angle prosthesis may induce post-surgery apparent leg discrepancies with functional and esthetical problems. Anthropometric variations were considered by introducing modifications to the neck angulations. Different neck angular variations were analyzed, ranging from $110^{\circ}$ to $160^{\circ}$ (Figure 4), in order to evaluate this anthropometric conditions and their effects on transmitted stresses and displacements.

\section{Results}

The first set of results refers to forces applied to the femoral neck which are transmitted to the implant and bones. Relationships between applied force and 
maximum Von Mises Equivalent Stresses are illustrated in Figure 5a, showing that the slope of stresses increases with increasing length of exposed fins.

The static analysis with finite element method provides not only stress distribution but the stress-displacement response of the prostheses, as

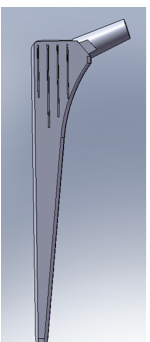

$110^{\circ}$

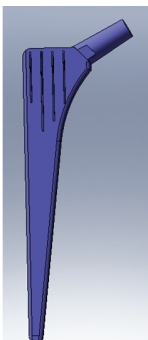

$120^{\circ}$

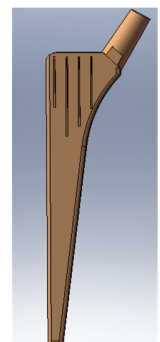

$150^{\circ}$

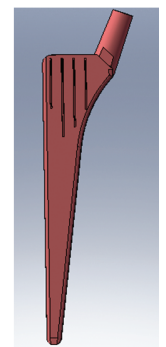

$160^{\circ}$
Figure 4. Extra neck angulations designed to simulate anthropometric variations (commercial prostheses is $135^{\circ}$ ).

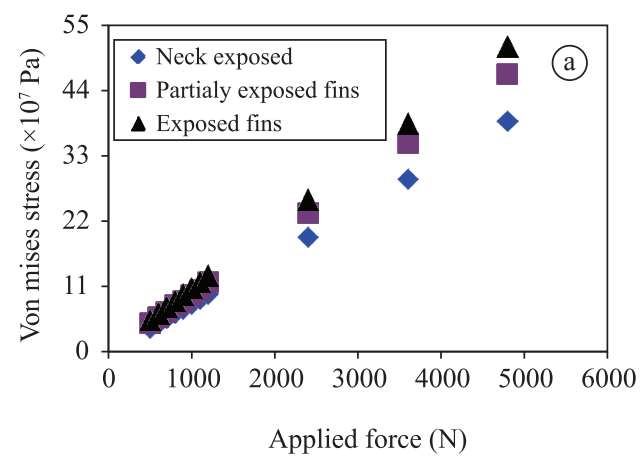

shown in Figure 5b. In this figure it is possible to observe that for a given force, displacements increase with the increase of exposed fins. In the three studied conditions the maximum mobilized displacement is of the order of 20 to $100 \times 10^{-5} \mathrm{~m}$ to a maximum applied force of $4800 \mathrm{~N}$.

An example of the stress-displacement distribution along a cross-section of the hip stem for an applied load of $1200 \mathrm{~N}$ is illustrated in Figure 6. The upper line Figures 6a-c represents the displacement field whereas the lower line Figures 6d-f shows the Von Mises Equivalent Stress field distribution. By analyzing all three conditions, stem with exposed fins (simulating an endoprostheses) showed total deformations progressively occurring from neck base to distal prostheses. When evaluating the mobilized stresses, a stress field concentration is observed at the contact of the neck region and the bone interface for the condition of neck exposed only (Figure 6d). Stresses

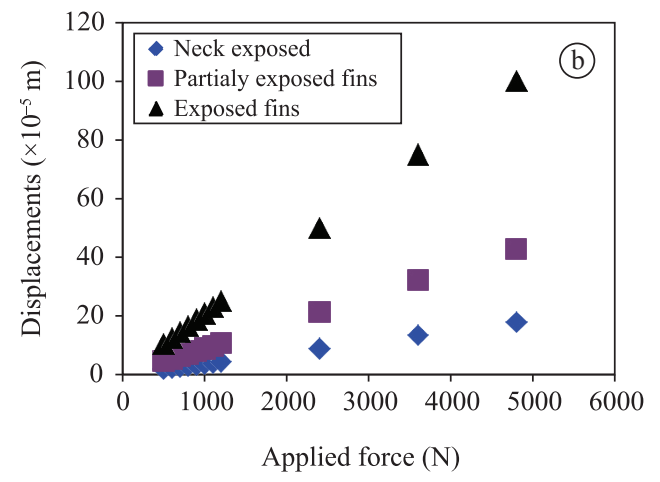

Figure 5. Relationship between: a) applied forces and maximum Von Mises Equivalent Stress; and b) applied forces and maximum stem displacement.

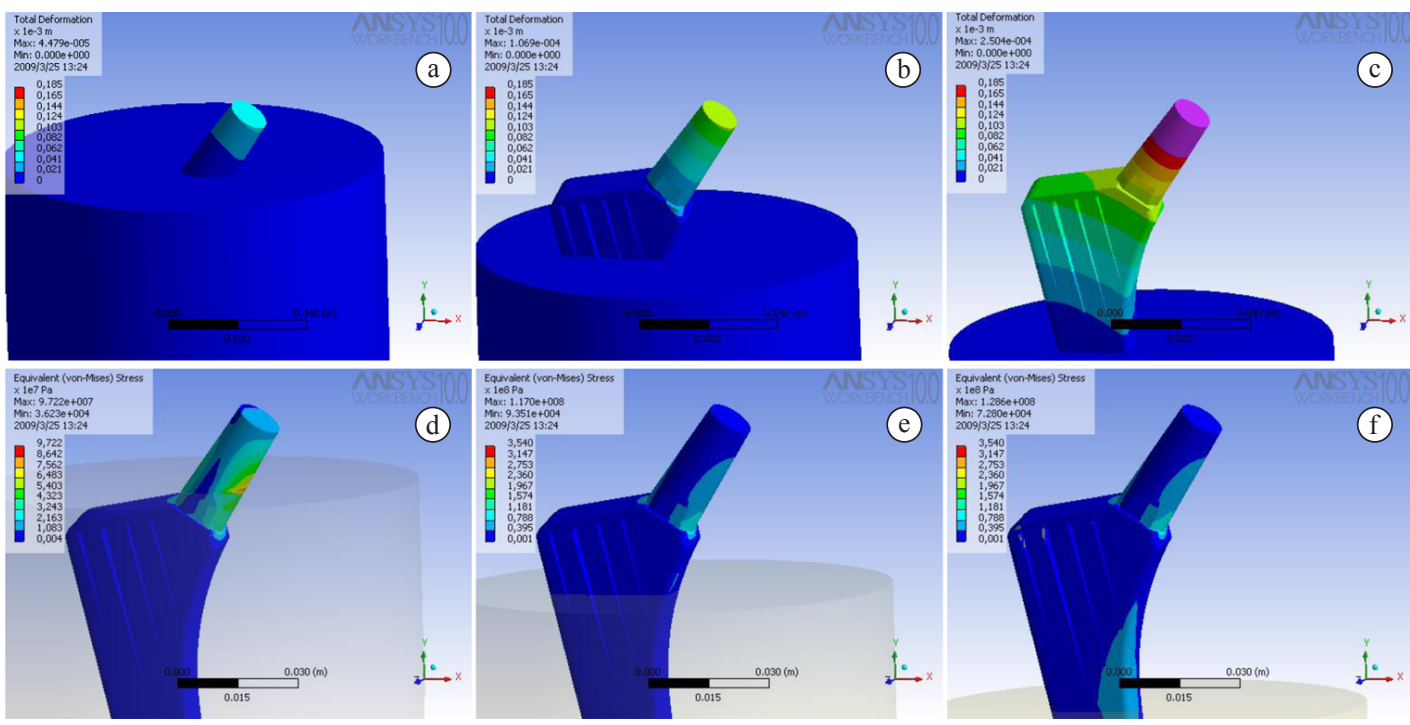

Figure 6. Example of numerical results in terms of total deformations ( $(a, b, c)$ and Von Mises Equivalent Stress (d, e, f) for the three conditions evaluated (only neck exposed, partially exposed fins, and fully exposed fins) for $1200 \mathrm{~N}$. 
are distributed over a larger area throughout prostheses as fins became exposed (Figure 6e). Two points of higher stress were observed when fins were totally exposed (Figure 6f), which are located at the neck and at the transition to the bone. In the condition of an exposed neck, stress concentration is only at the neck bases whereas other conditions show a progressive stress towards the transition to the bone. This described behavior becomes clear in Figure 7, in which normalized displacements are plotted against normalized Von Misses Equivalent Stress. The yield stress and corresponding critical displacement have been measured by uniaxial compressive laboratory tests (Macedo, 2007; Macedo et al., 2008). A linear normalized stress-strain relationship is observed in this figure with a maximum stress ratio of about 0.45 for the most commonly used configuration indicating a high factor of safety under static loading. Even for the worst condition, stress ratio is about 0.55 .

When gait cycle is considered, the worst condition is for 90 degrees flexion. Standard use (only neck exposed) reaches 0.54 , still having a good safety factor, whereas partially exposed fins reaches 0.81 and totally exposed reaches 0.83 .

Figures $8 \mathrm{a}, \mathrm{b}$ present the relationship between stem neck variation with maximum calculated Von Mises

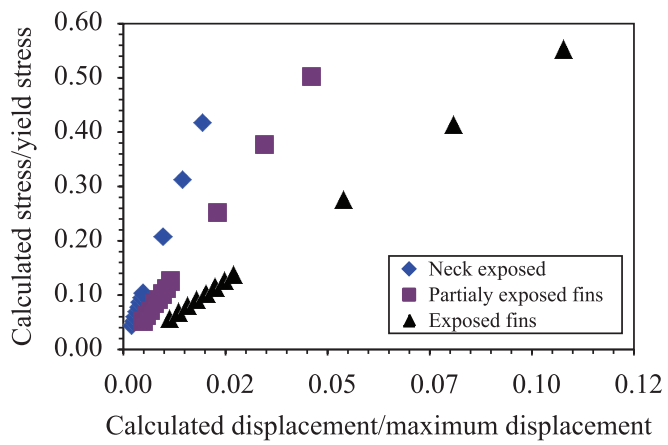

Figure 7. Normalized Von Mises Equivalent Stress/Yield Stress versus normalized calculated displacements/Maximum Displacements.

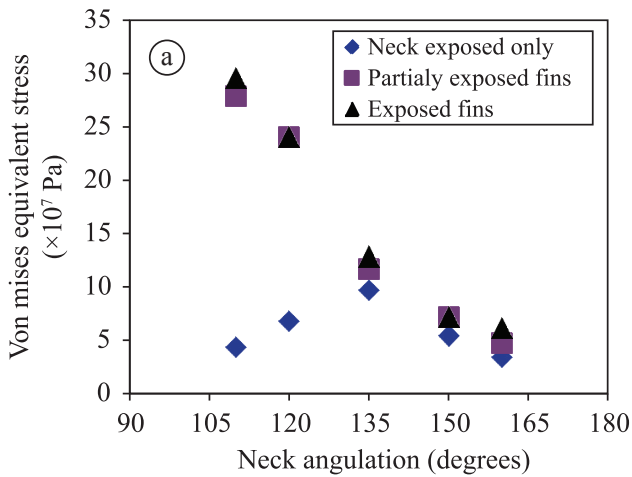

Equivalent Stress and maximum calculated displacement respectively. A non-linear relationship is observed in all cases with applied forces generally increasing with reducing neck angulation. For neck angulations lower than $135^{\circ}$, the exposed fins condition generates stress that is higher for a fully embedded neck. A completely buried prostheses generates mobilized stress lower than $10 \times 10^{7}$ Pa yielding total deformations as small as $5 \times 10^{-5} \mathrm{~m}$. Partially or totally exposed fins show almost no stress distribution differences, but the displacements increase significantly for the case of totally exposed fins. Variations on total deformations range from 5 to $15 \times 10^{-5} \mathrm{~m}$ and 20 to $30 \times 10^{-5} \mathrm{~m}$ for partially or totally exposed fins, respectively (Figure 8b). These values can be represented in a normalized fashion as illustrated in Figure 7 to yield data shown in Figure 9. A non-linear relationship is observed for all studied cases, showing that a given normalized stress and normalized displacements increase considerably with increasing exposition of fins.

\section{Discussion}

Forces applied to the femoral neck are transmitted to the implant and bones, and the slope of stresses and displacements increases with increasing length of exposed fins. In practice, however, there are no major differences among the three cases because the mobilized stress is about $50 \%$ of the laboratory measured yield stress. This find is on itself an essential feature in the hip design, because the implant is dynamically loaded and severe fatigue damage can be produced. Since this study is concentrated on static loading, the static result can be used to evaluate the fatigue life of the component if inertial effects are neglected.

When evaluating the mobilized stresses, the stress field concentration is different for the three conditions proposed in this work. The linear stress-strain has a maximum stress ratio of about 0.55 indicating a

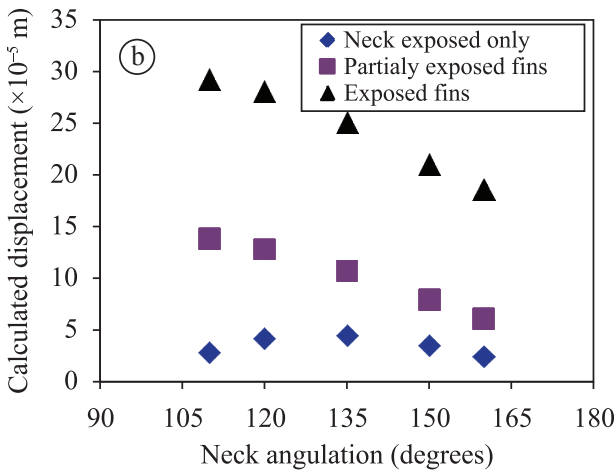

Figure 8. a) Stem neck angle variation versus Von Mises Equivalent Stress; and b) stem neck angle variation versus calculated displacement. 


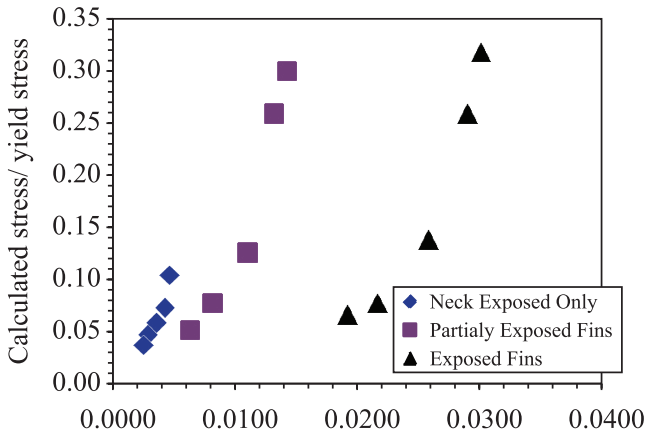

Calculated displacement/maximum displacement

Figure 9. Normalized calculated Von Mises Equivalent Stress/ Yield Stress versus normalized calculated displacements/Maximum displacements for all different neck angulations.

good factor of safety under static loading. Although maximum normalized displacements are lower than 0.12 for the worst conditions, displacements increase considerably for the condition of exposed fins, which may increase future risk of bone fracture. The numerical analysis has not modeled fracture effects, since it would depend on bone mineral density and in this case bone anisotropy, directions and magnitude of transmitted forces, prostheses migration and rotation, among other factors, should be considered on the numerical model.

A non-linear relationship was observed in all cases when neck angles variations were considered. Normalized stress and normalized displacements increase considerably with increasing exposition of fins. Moreover, mobilized stresses and displacements are lower for the valgus condition $\left(160^{\circ}\right)$ and increase as the prostheses became varus $\left(110^{\circ}\right)$, as illustrated in Figure 4.

The stress distribution on the bone interface has important implications. Higher Young Modulus stems transfers less stresses to the bone, inducing stress-shield effect, and increasing applied forces transfers higher stresses to the bone, as well for increasing exposed fins. This information is better understood when calculated values are normalized by the bone ultimate stress of $224 \mathrm{MPa}$ (see Table 1), yielding a maximum normalized stress of about $50 \%$. Anthropometric variations studied in this research program indicated similar patterns for $110^{\circ}$ to $160^{\circ}$.

Although numerical analysis is a highly specialized subject, an attempt was made to narrow the gap between specialized researchers and practicing medical doctors, who may not be familiar with detailed numerical methodologies but have the need to incorporate new concepts into design to provide safer and more economical prostheses. First it is important recognizing that computational analysis is now becoming accepted in biomechanics as a mean of decreasing the number of individuals needed in research, as well as to decrease costs in developing prototype prostheses. ASTM F2514-08 (American..., 2008b), Standard Guide for Finite Element Analysis of Metallic Vascular Stents Subjected to Uniform Radial Loading, is an example.

The femoral hip design investigated in the present study complies with medical standards (ASTM and ISO/ABNT/NBR Standards) and has gone through a series of rigorous tests before being commercially launched. Finite element analysis provide means of optimizing the hip prostheses design and perform pre-clinical evaluation (Huiskes and Vroemen, 1986; Huiskes et al., 1977), as presented in this research.

\section{Conclusions}

Numerical analysis of Logical uncemented femoral stem demonstrated that current design successfully meets specific project goals and objectives. Small stresses and displacements are generated under working load conditions to the stem indicating that a proper factor of safety is obtained for the static conditions tested in the present study. The stem performance is shown to be fairly sensitive to both the length of exposed fins and the neck angle variation. These evidences give room to a number of recommendations. Stem displacements increase significantly with the increase length of exposed fins, and even for the extreme situation of totally exposed fins, the prostheses will support the working loads, but the risk of bone fracture may increase due to increasing displacements.

The sensitivity to neck angulations indicates that anthropometric variations should be considered in order to obtain best functional results. In addition to pre-clinical testing, patient-specific models may have a future potential to be used directly in clinical practice and on patient management in a number of ways, including assessment of the mechanical aspects preoperatively, select appropriate devices for each biological and non-biological variability (material properties, design options, geometry), predict load transfer stress distribution after surgery and estimate long term performance of the procedure.

\section{Acknowledgements}

This research program has been developed at the University Hospital at Federal University of Rio Grande do Sul, Brazil. The numerical study was supported by the Civil and Mechanical Post-Graduation 
Program at the same university, being supported by Brazilian National Program for Post-Doctoral AUX-PE-PNPD:1517/2008. The authors also would like to thanks to Dr. Luis Fernando Moreira for his important contribution to the research.

\section{References}

Associação Brasileira de Normas Técnicas - ABNT. ABNT NBR ISO 5832-3: Implants for surgery - Metallic materials Part 3: Wrought titanium 6-aluminium 4-vanadium alloy. ABNT; 1997.

Ahmet CC, Ucar V, Kazan R. Three-dimensional anatomic finite element modelling of hemi-arthroplasty of human hip joit. Trends in Biomaterials \& Artificial Organs. 2007; 21:63-72.

American Society for Testing and Materials - ASTM. ASTM F136-08e1: Standard specification for wrought Titanium-6 Aluminum-4 Vanadium ELI (Extra Low Interstitial) alloy for surgical implant applications (UNS R56401). West Conshohocken: ASTM International; 2008a. 5 p.

American Society for Testing and Materials - ASTM. ASTM F2514-08 - Standard guide for finite element analysis of metallic vascular stents Subjected to uniform radial loading. West Conshohocken: ASTM International; 2008b. 8 p.

Bennet D, Goswami T. Finite element analysis of hip stem designs. Materials and Design. 2008; 29:45-60. http://dx.doi. org/10.1016/j.matdes.2006.12.014

Brekelmans WAM, Poort H, Slooff TJJH. A new method to analyse the mechanical behaviour of skeletal parts. Acta Orthopaedica Scandinavica. 1972; 43(5):301-17. http:// dx.doi.org/10.3109/17453677208998949

Brown TD, Callaghan JJ. Impingement in total hip replacement: mechanisms and consequences. Current Orthopaedics. 2008; 22:376-91. PMid:19956356 PMCid:2652485. http://dx.doi.org/10.1016/j.cuor.2008.10.009

Fagan MJ, Lee AJC. Material selection in the design of the femoral component of cemented total hip replacements. Clinical Materials. 1986; 1:151-67. http://dx.doi.org/10.1016/ S0267-6605(86)80029-4

Fernandes PR, Folgado J, Ruben RB. Shape optimization of a cementless hip stem for a minimum of interface stress and displacement. Computer Methods in Biomechanics and Biomedical Engineering. 2004; 7(1): 51-61. PMid:14965880. http://dx.doi.org/10.1080/10255840410001661637

Harkess JW, Crockarell JR. Arthroplasty of the hip. In: Canale ST, Beaty JH, editors. Campbell's Operative Orthopaedics. 11th ed. Philadelphia: Mosby Elsevier; 2007. chap. 7, $314 \mathrm{p}$.

Huiskes R. Biomechanics of artificial-joint fixation. In: Mow VC, Hayes WC, editors. Basic orthopaedic biomechanics. New York: Raven Press; 1991. p. 375-442.

Huiskes R, Slooff TJJH, Elangovan PT, Banens JPA. Finite element computer methods for design and fixation problems of orthopaedic implants. Computer Methods in Biomechanics and Biomedical Engineering. 1977; 229-38.
Huiskes R, Van Rietbergen B. Preclinical testing of total hip stems: the effects of coating placement. Clinical Orthopaedics and Related Research. 1995; 319:64-76. PMid:7554651.

Huiskes R, Vroemen WA. A standardized finite element model for routine comparative evaluations of femoral hip prostheses. Acta Orthopaedica Belgica. 1986; 52:258-61. PMid:3788510.

Jones AC. Introduction to finite element analysis. Leeds: Finite Element Analysis for Orthopaedic Design; 2009.

Keaveny TM, Bartel DL. Effects of porous coating with and without collar support, on early relative motion for cementless hip prostheses. Journal of Biomechanics. 1993; 26:1355-68. http://dx.doi.org/10.1016/0021-9290(93)90087-U

Kluess D, Souffrant R, Mittelmeier W, Wree A, Schmitz K-P, Bader R. A convenient approach for finite-element-analyses of orthopaedic implants in bone contact: modelling and experimental validation. Computer Methods and Programs in Biomedicine. 2009; 95(1):23-30. PMid:19231021. http:// dx.doi.org/10.1016/j.cmpb.2009.01.004

Lee AJC. Finite element analysis and its significance in total hip replacement. In: Stillwell WT, editor. The art of total hip arthroplasty. Orlando: Grune \& Stratton; 1987. p. 33-9.

Lewis CL, Sahrmann SA, Moran DW. Effect of hip angle on anterior hip joint force during gait. Gait \& Posture. 2010; 32(4):603-7. http://dx.doi.org/10.1016/j. gaitpost.2010.09.001

Macedo CAS. Developing national cementless stem, validated by international standards [thesis]. Porto Alegre: Federal University of Rio Grande do Sul; 2007. 121 p.

Macedo CAS, Galia CR, Moreira LF, Rosito R, Macedo FCS, Hübler R. Characterization of a cementless Ti-6Al-4V femoral stem. Brazilian Journal of Biomedical Engineering. 2008; 24(3):183-92.

McNamara BP, Taylor D, Prendergast PJ. Computer prediction of adaptative bone remodelling around noncemented femoral prostheses: the relationship between damage-based and strain-based algorithms. Medical Engineering \& Physics. 1997; 19(5):454-63. http://dx.doi.org/10.1016/ S1350-4533(97)00002-7

Prendergast PJ. Finite element models in tissue mechanics and orthopaedic implant design. Clinical Biomechanics. 1997; 12(6):343-66. http://dx.doi.org/10.1016/ S0268-0033(97)00018-1

Prendergast PJ, Monaghan J, Taylor D. Materials selection in the artificial hip joint using finite element stress analysis. Clinical Materials. 1989; 4:361-76. http://dx.doi. org/10.1016/0267-6605(89)90016-4

Sakai R, Sato Y, Itoman M, Mabuchi K. Initial fixation of a finite element model of an AI-Hip cementless stem evaluated by micromotion and stress. Journal of Orthopaedic Science. 2010; 15:132-9. PMid:20151263. http://dx.doi. org/10.1007/s00776-009-1422-Z

Tanner KE, Yettram AL, Loeffler M, Goodier WD, Freeman MAR, Bonfield W. Is stem length important in uncemented endoprostheses? Medical Engineering \& 
Physics. 1995; 17(4):291-6. http://dx.doi.org/10.1016/13504533(95)90854-5

Verdonschot NJJ. Biomechanical failure scenarios for cemented total hip replacement [thesis]. The Netherlands: University of Nijmegen; 1995.

Verdonschot NJJ, Huiskes R, Freeman MAR. Pre-clinical testing of hip prosthetic designs: a comparison of finite element calculations and laboratory tests. London: The Institute of Mechanical Engineering; 1993. p.149-54
Yettram AL. Effect of interface conditions on the behaviour of a Freeman hip endoprosthesis. Journal of Biomedical Engineering. 1989; 11:520-4. http://dx.doi.org/10.1016/01415425(89)90048-4

Yu SH, Ville JST, Rajan SD. Inverse design techniques for improving composite prosthetic devices. Engineering Optimization. 2002; 34(5):427-43. http://dx.doi. org/10.1080/03052150214018

\section{Authors}

\section{Leandro de Freitas Spinelli*}

Post-Doctoral Program in Engineering, Federal University of Rio Grande do Sul - UFRGS,

Fellowship Program in Hip Surgery, Clinics Hospital, Federal University of Rio Grande do Sul - UFRGS,

Rua Ramiro Barcelos, 1323/701, CEP 90035-006, Porto Alegre, RS, Brazil

Carlos Alberto de Souza Macedo, Carlos Roberto Galia, Ricardo Rosito

Department of Orthopedics, Faculty Hospital, Federal University of Rio Grande do Sul - UFRGS,

Rua Ramiro Barcelos, 2350, Largo Eduardo Zaccaro Faraco, CEP 90035-003, Porto Alegre, RS, Brazil

\section{Fernando Schnaid}

Department of Civil Engineering, Federal University of Rio Grande do Sul - UFRGS,

Av. Osvaldo Aranha, 99/3 andar, CEP 90035-190, Porto Alegre, RS, Brazil

\section{Leandro Luis Corso, Ignácio Iturrioz}

Department of Mechanical Engineering, Federal University of Rio Grande do Sul - UFRGS, Av. Sarmento Leite, 425, Vibration Laboratory, CEP 90050-170, Porto Alegre, RS, Brazil 